Received Date : 27-Aug-2015

Revised Date : 30-Mar-2016

Accepted Date : 25-Apr-2016

Article type : Original Article

6

7

\title{
Turnover of village chickens undermines vaccine coverage to control HPAI H5N1
}

\section{J.P. Villanueva-Cabezas ${ }^{1,2}$, P.T. Campbell ${ }^{1,3}$, J.M. McCaw ${ }^{1,3,4}$, P.A. Durr ${ }^{2}$, J. McVernon ${ }^{1,3}$}

${ }^{1}$ Centre for Epidemiology and Biostatistics, Melbourne School of Population and Global Health,

University of Melbourne, Melbourne, Australia

${ }^{2}$ Australian Animal Health Laboratory, CSIRO, Geelong, Victoria, Australia.

${ }^{3}$ Modelling and Simulation Research Group, Murdoch Childrens Research Institute, Royal Children's Hospital, Parkville, Victoria, Australia.

${ }^{4}$ School of Mathematics and Statistics, The University of Melbourne, Melbourne, Australia

Corresponding author: J.P. Villanueva-Cabezas |juanvc@student.unimelb.edu.au

Summary: Highly pathogenic avian influenza (HPAI) subtype H5N1 remains an enzootic disease of village chickens in Indonesia, posing ongoing risk at the animal-human interface. Previous modelling showed that the fast natural turnover of chicken populations might undermine herd immunity after vaccination, although actual details of how this effect applies to Indonesia's village chicken population have not been determined. We explored the turnover effect in Indonesia's scavenging and mixed populations of village chickens using an extended Leslie Matrix model parameterized with data collected from village chicken flocks in Java region, Indonesia. Population dynamics were simulated for 208 weeks; the turnover effect was This is the author manuscript accepted for publication and has undergone full peer review but has not been through the copyediting, typesetting, pagination and proofreading process, which may lead to differences between this version and the Version of Record. Please cite this article as doi: $\underline{10.1111 / \text { zph.12282 }}$ 
simulated for 16 weeks after vaccination in two 'best case' scenarios, where the whole

2 population (scenario 1), or birds over 14 day-old (scenario 2), were vaccinated. We found that

the scavenging and mixed populations have different productive traits. When steady-state

4 dynamics are reached, both populations are dominated by females (54.5\%), and "growers" and

5 "chicks" represent the most abundant age-stages with $39 \%$ and $38 \%$ in the scavenging, and $60 \%$ and $25 \%$ in the mixed population, respectively. Simulations showed that the population turnover might reduce the herd immunity below the critical threshold that prevents the reemergence of

8 HPAI H5N1 4 to 8 weeks (scavenging) and 6 to 9 weeks (mixed population) after vaccination in scenario 1, and 2 to 6 weeks (scavenging) and 4 to 7 weeks (mixed population) after vaccination in scenario 2. In conclusion, we found that Indonesia's village chicken population does not have a unique underlying population dynamic and therefore, different turnover effects on herd immunity may be expected after vaccination; nonetheless, our simulations carried out in best case scenarios highlight the limitations of current vaccine technologies to control HPAI H5N1. This suggests that improvements and complementary strategies are necessary and must be explored.

Keywords: Avian influenza, poultry, population dynamics, mathematical modelling

\section{Impact}

- Village poultry infected with HPAI H5N1 remain a risk at the animal-human interface within Indonesia;

- We explored two population dynamics coexisting amongst the Indonesian village chickens

2 that could have different impact on the effectiveness of vaccine interventions and duration of adequate herd immunity;

- Our simulations highlight the importance of developing separated demographic models for the Indonesian sector 4 when planning vaccine strategies to control HPAI H5N1.

\section{Introduction}

28 The emergence and reemergence of zoonotic diseases during the last three decades has prompted 29 a holistic approach to public health, with the aim of attaining the best health possible for humans and animals, the effort being called 'One Health' (Zinsstag et al., 2015). In this context, the

31 World Health Organization (WHO), the World Organization of Animal Health (OIE), and the 
1 Food and Agriculture Organization of the United Nations (FAO) formed an alliance to consider 2 the challenges posed by highly pathogenic avian influenza (HPAI) subtype H5N1 in countries of Asia and Africa (FAO/OIE/WHO, 2010a). This alliance called for further research including the

4 study of animal and human population dynamics as a priority (FAO/OIE/WHO, 2010b) to

5 further understand their role in spreading zoonotic HPAI at the animal-human interface.

6 As of 2016, 63 countries have reported circulation of HPAI H5N1 among poultry 7 (EMPRES/FAO-GLEWS, 2012) and 16 have reported human cases (World Health Organization, 8 2015a). Among them, Indonesia is one of the most severely affected, reporting enzootic 9 circulation of the virus at the poultry level (World Health Organization, 2013) and the world's 10 second largest number of human reported cases, after Egypt (World Health Organization, 11 2015a). Undoubtedly, the control of HPAI H5N1 in Indonesia is a complex public health 12 challenge since over 60\% of the households keep village chickens (Farnsworth et al., 2011), a 13 backyard production with subsistence or side business purposes. These productions, denominated "sector 4", generally lack biosecurity measures (FAO, 2008a) and, therefore, are presumed to have an important role in the circulation of HPAI H5N1 (Sims et al., 2005). In 2004, the Indonesian government implemented a vaccination plan designed to generate herd immunity in these flocks and reduce the circulation of this virus (Siregar et al., 2007).

Since 2009, Indonesia has successfully been able to keep HPAI H5N1 under control which has reduced the number of new human cases (World Health Organization, 2015a) and the number of poultry outbreaks (EMPRES/FAO, 2012) although these continue to be reported (EMPRES-i FAO, 2015). It is not completely clear how poultry in sector 4 contribute to sustain HPAI H5N1 in Indonesia; however, the low biosecurity, the discontinuous mass vaccination programs, and the fast turnover that increases the number of influenza-susceptible individuals undermining the herd immunity, might imply that the village chicken population is a reservoir that sporadically infects the commercial sector and the human population.

To date, there are no studies specifically investigating Indonesia's village chicken population dynamics and their effect on vaccine interventions to control HPAI H5N1. With the objective of overcoming this limitation, we model the Indonesian village chicken population whereby we simulate population dynamics with the specific aim to assess the effect of the turnover on the achievable herd immunity after vaccination. 


\section{Village Chickens parameters}

We undertook a detailed review of the formal and informal literature on the population dynamics

4 of village chicken populations in Indonesia and the region. This showed a general tendency to treat the village chicken population as homogeneous, comprising free-range scavenging birds (Siregar et al., 2007, FAO, 2009b, ILRI, 2011, Unger et al., 2012). However, a more careful revision indicates the existence of subpopulations of village chickens according to the rearing system: the "traditional", where birds are left to scavenge freely in the village without farmer's management or care; the "semi-improved", where birds receive feed and some health care; and the "improved" where birds are fed, cared for, separated by age-stage, and is fully businessoriented in contrast with the traditional and semi-improved (FAO, 2008b). The scavenging (or traditional) system remains the most popular in Indonesia because most villagers are unable or unwilling to initiate commercialized production (FAO, 2008b).

There is limited literature on the demographic and production traits of the current scavenging village populations; however, as this system is resistant to change (Alders \& Pym, 2009), we considered that a detailed investigation undertaken in the 1970s (Kingston, 1980), is likely to remain relevant. We did not find specific literature describing the semi-improved or improved village production populations; however, a detailed survey of village production was undertaken in West and Central Java in 2008 (FAO, 2009b) in which average parameters for the three subpopulations were provided. The traits described in this survey resemble a "mixed" farming system as described by Handaka (2009) where birds are obtained on-farm or with some purchase, production is partly consumed and partly sold in markets, and rearing poultry is deemed a diversification for family income. Therefore, we parameterized a scavenging and a mixed population of Indonesian village chickens, with data collected in the Java region.

The scavenging and mixed populations were divided into four gender-specific age-stages including eggs, chicks (<1 month), growers (1-6 months), and adults (> 6 months). For model purposes, duration of age-stages was counted in weeks. Female reproductive output was calculated using the number of eggs described in Kingston (1980) and the clutches/hen/year in FAO (2009b). Eggs and chicks were anticipated to be of ratio 1:1 female: male, based on scientific observations (Parker \& Winker, 2005). Survivorship for eggs and chicks were 
calculated using the reported abundance of individuals at different times of each particular agestage (Kingston, 1980, FAO, 2009b). Given the lack of information on overall survivorship for growers and adult village chickens in the Indonesian context, these were estimated to be $30 \%$ and $20 \%$ for female and male growers, and $20 \%$ and $10 \%$ for hens and cocks based on the average flock structure of village chickens in Java (FAO, 2009b). The maximum age for adults for the scavenging chicken population was set to two years for hens and one and a half years for cocks (Diwyanto \& Iskandar, 1999). We assumed a maximum age of one year for hens and cocks in the mixed population.

\section{Demographic Model}

We broadly used the demographic matrix modelling approach published by Lesnoff et al. (2009), wherein the turnover of a free-range chicken population characteristic of the African context and its effect on the herd immunity after vaccination were simulated. Lesnoff et al model extends upon the classic Leslie Matrix Model based on methods published elsewhere (Crouse et al., 1987, Caswell, 2001, Skalski et al., 2010). Given the limited husbandry that village chickens receive in the Indonesian context (Kingston, 1980, Aini, 1990, FAO, 2008a, FAO, 2009b) which compromises the ascertainment of detailed age-specific parameters and population counts for these birds, we used an aggregated modelling approach reflecting age-stages.

Lesnoff et al model respects most of the classic Leslie Matrix Model characteristics but acknowledges that age-stages may differ in duration. Additionally, their model allows the inclusion of both female and male parameters (Skalski et al., 2010, Lefkovitch, 1965). Thus, in our aggregated version of Lesnoff et al model the projection matrix (A) includes the female reproductive output, and the survivorship within and between age-stages for both genders; the population vector $(\mathrm{N})$ includes the female and male abundance in every age-stage. The general model is denoted:

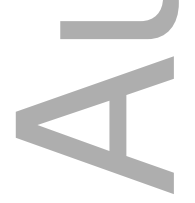




$\left[\begin{array}{cccc|cccc}P_{1 f} & F_{2 f} & . F_{3 f} & F_{4 f} & 0 & 0 & 0 & 0 \\ S_{1 f} & P_{2 f} & 0 & 0 & 0 & 0 & 0 & 0 \\ 0 & S_{2 f} & P_{3 f} & 0 & 0 & 0 & 0 & 0 \\ 0 & 0 & S_{3 f} & P_{4 f} & 0 & 0 & 0 & 0 \\ \hline F_{1 m} & F_{2 m} & F_{3 m} & F_{4 m} & P_{1 m} & 0 & 0 & 0 \\ 0 & 0 & 0 & 0 & S_{1 m} & P_{2 m} & 0 & 0 \\ 0 & 0 & 0 & 0 & 0 & S_{2 m} & P_{3 m} & 0 \\ 0 & 0 & 0 & 0 & 0 & 0 & S_{3 m} & P_{4 m}\end{array}\right]$

$*\left[\begin{array}{c}n_{1 f} \\ n_{2 f} \\ n_{3 f} \\ n_{4 f} \\ n_{1 m} \\ n_{2 m} \\ n_{3 m} \\ n_{4 m}\end{array}\right]_{t}$

$\left[\begin{array}{l}n_{1 f} \\ n_{2 f} \\ n_{3 f} \\ n_{4 f} \\ n_{1 m} \\ n_{2 m} \\ n_{3 m} \\ n_{4 m}\end{array}\right]_{t+\Delta t}$

where the upper-left matrix is the original Leslie Matrix (Leslie, 1945, Leslie, 1948) including the number of females born from a female in each age-stage $\left(\mathrm{F}_{\mathrm{xf}}\right)$, the female probability of surviving and remaining within the same age-stage $\left(\mathrm{P}_{\mathrm{xf}}\right)$, and the probability of surviving an agestage and passing to the next $\left(\mathrm{S}_{\mathrm{xf}}\right)$; the lower left matrix is the number of males born from a female in each age-stage $\left(\mathrm{F}_{\mathrm{xm}}\right)$; the lower-right matrix is the male probability of surviving and remaining within the same age-stage $\left(\mathrm{P}_{\mathrm{xm}}\right)$, and the probability of surviving an age-stage and passing to the next $\left(\mathrm{S}_{\mathrm{xm}}\right)$. The upper-right matrix is completed with zero (males do not have offspring). The $n_{\mathrm{xf}}, n_{\mathrm{xm}}$ values in population vectors $\mathrm{N}_{\mathrm{t}}$ and $\mathrm{N}_{\mathrm{t}+\Delta \mathrm{t}}$, represent the female and male abundance in each age-stage at time $t$ and $t+\Delta t$, respectively. This model allows for calculation of the multiplicative factor of change in population size from one time period to the next, $\lambda$; and the relative gender-age-stage abundance in a stable population (Skalski et al., 2010). Demographic traits are in Table 1; detailed calculations of the model's parameters are in Supplement 1.

For each of the scavenging and mixed populations, population dynamics were simulated as follows: matrix A was filled with the fixed parameter values in Supplement 1 derived from population traits in Table 1. A starting population based on the number of households and average number of chickens per flock in Central Java was estimated; then, the relative abundance of age-stages in these flocks (FAO, 2009b) was directly extrapolated to the starting population to produce the distribution included in vector $\mathrm{N}$ for week 0 . This extrapolation is possible since Leslie Matrix models produce a unique relative age-stage abundance when steady-state dynamics

22 are reached, regardless of the initial distribution included in vector $\mathrm{N}$; therefore, the relative agestage abundance is characterized by the parameter values included in matrix A (Caswell, 2001, Skalski et al., 2010). Population dynamics were simulated in R software (R Development Core 
1 Team, 2014) for 208 weeks, until the populations reached steady-state dynamics. Given that the

2 average Indonesian village chicken population is fairly stable (Unger et al., 2012), in a final step

3 we compared our projection of steady-state relative age-stage distribution for the scavenging and

4 mixed populations against validation data of the Javanese village chicken population (ILRI,

5 2011).

6 Simulation of a vaceine intervention for H5N1

7 Two "best vaccine intervention scenarios" were simulated in which all birds are 8 immunocompetent, one dose is enough to provide effective immunization, birds become 9 immediately immune after vaccination (100\% immune response), and 100\% of target birds are 10 vaccinated. Simulations allowed estimation of the population turnover effect alone on the 11 achievable herd immunity level, and the number of weeks after vaccination the herd immunity 12 lasts before reaching the herd immunity critical threshold that prevents viral reemergence. This 13 critical herd immunity threshold was estimated to lie between $50 \%$ to $67 \%$, calculated as in Fine et al. (2011), using the $\mathrm{R}_{0}$ reported in Ward et al. (2009) and Tiensin et al.(2007).

Once the population achieved steady-state dynamics, vaccination was implemented at a single time. Village flocks in Indonesia have been recommended to be vaccinated twice, with an interval period of approximately 14 weeks (Bouma et al., 2008); we assumed that a second vaccination could be completed up to 16 weeks after the first intervention since logistic difficulties are often reported (Siregar et al., 2007, Bouma et al., 2008). Thus, simulation of herd immunity after vaccination was conducted in two scenarios: the whole population is vaccinated (scenario 1) or only those $>14$ day-old received the vaccine (scenario 2 ).

Population turnover was assumed to be driven by birth and removal (death, consumption or sale) of birds from the population; however, purchase of chicks also occurs in the "mixed" population (FAO, 2009b, Handaka, 2009). Chicks born were calculated based on hen and egg parameters of fertility and survival included in Table 1 . The population removed was estimated for every week to avoid overestimating the number of individuals susceptible to H5N1. Detailed calculation of herd immunity after vaccination is in Supplement 2.

We conducted an uncertainty analysis to determine the robustness of herd immunity estimates to variations in model parameters. Data from Indonesia and Asia (Kingston et al., 1982, Cumming, 
1992, Gunaratne et al., 1993, FAO, 2009b) were collated to estimate triangular densities

2 (minimum, maximum, and most likely values) for each parameter. Population dynamics were

3 simulated for sets of parameters randomly selected from triangular densities (Supplement 2)

4 using Latin Hypercube Sampling (McKay et al., 1979); those sets producing variations of

5 population abundance larger than $2 \%$ per week were excluded from our analysis to reflect the stability of the village chicken population over time (Unger et al., 2012). Finally, we conducted a sensitivity analysis based on partial rank correlation coefficients (PRCC) (Marino et al., 2008) to measure the strength of association between each model parameter and the herd immunity in scenario 1 and 2. Coefficients were calculated for the herd immunity in week 7 post-vaccination, because this time point represents an intermediate time in our simulations.

\section{Results}

\section{Village chicken parameters}

The demographics of the scavenging and mixed village chicken populations (Table 1) show that the average number of eggs per hen in the scavenging population is - perhaps surprisingly higher than in the mixed; however, when chicks hatch, the weekly survival of scavenging chicks is about $23 \%$ less than the survival of chicks in the mixed population. This means the number of growers surviving weekly in the scavenging population is lower compared to the mixed, despite the same probability of weekly survivorship in this age-stage. However, the few adults in the scavenging population have a better probability of weekly survival given their longer life expectancy

Direct comparison of the modelled Indonesian village populations with the generalized African free-range chicken population results given by Lesnoff et al (2009) is not straight forward since the duration of age-stages has been estimated differently. However, comparing the model inputs shows that the number of eggs in the African system is lower than that expected in the Indonesian populations, the overall survival of African chicks in 10 weeks is equal to that of the Indonesian scavenging chicks at 4 weeks, and adults in African flocks have higher probability of weekly survival than those in any Indonesian village chicken population.

\section{Demographic model and projections}


Both the scavenging and mixed populations achieved steady-state dynamics producing

2 populations with stable relative age-stage distribution characterized by the best parameter value estimates included in matrix A. When such steady-state dynamics are reached, the scavenging population is dominated by growers and chicks (39\% and $38 \%$ respectively, females and males combined); hens make up $16 \%$ of the population and cocks $7 \%$. The mixed village chicken population is also dominated by growers, although here they represent over half of the population ( $60 \%$ females and males combined); chicks are $25 \%$ of the individuals while hens and cocks represent $12 \%$ and $6 \%$, respectively.

The multiplicative factor of change in population size from one time period to the next was estimated to be $\lambda_{\text {scavenging }}=1.002$ and $\lambda_{\text {mixed }}=0.998$. Where $\lambda=1$ represents no change in population size, the estimated values of $\lambda$ reflect marginal variation of population size in the period simulated.

When the model output for the scavenging and mixed populations were compared with the validation data (ILRI, 2011), the steady-state relative age-stage distribution of the mixed - but not that of scavenging village chickens - was generally consistent (Table 2).

\section{Simulation of a vaccine intervention for HPAI H5N1}

The simulation of 'best case scenarios' showed that the natural turnover of the scavenging and mixed village chicken population undermines the achievable herd immunity level conferred by vaccination in a short period of time.

When the intervention includes all birds, the herd immunity decreases to $84.7 \%$ and $93.2 \%$ one week after vaccination; by week 10, less than half of the population would be immune (40.5\% of the scavenging and $48.5 \%$ of the mixed population); 16 weeks after vaccination, the herd immunity would be only $29.5 \%$ and $31 \%$ for the scavenging and mixed population, respectively. Trends are more dramatic when only birds $>14$ days old are vaccinated. The day of vaccination, only $80.7 \%$ of the scavenging and $87.6 \%$ of the mixed population would be immune; one week after, the immune population drops to $71.3 \%$ and $81.5 \%$ respectively. By week 10, 37.8\% of the scavenging and $42.2 \%$ of the mixed chickens remain immune and only $27.7 \%$ and $26.9 \%$ keep that condition 16 weeks after the intervention (Figure 1). 
The uncertainty analysis showed that over a range of realistic parameter estimates, the time to

2 reach the herd immunity critical threshold is only a few weeks despite the simulations being perfect scenarios of vaccination (Figure 2). If all birds are vaccinated, the median time to reach the higher critical threshold (67\%) after vaccination would be 4 and 6 weeks (interquartile range 5 [iqr] $=5-6$ weeks) for the scavenging and mixed population, respectively, while the median time to reach the lower critical threshold $(50 \%)$, would be 8 weeks $($ iqr $=7-8)$ and 9 weeks $($ iqr $=8-$ 10) respectively. When only birds $>14$ days old are vaccinated, the higher threshold would be reached in a median time of 2 weeks (iqr $=2-3)$ in the scavenging and 4 weeks (iqr $=3-4)$ in the mixed population; the lower threshold would be reached in 6 weeks (iqr $=6-7$ ) and 7 weeks (iqr =7-8) respectively. These median times are consistent with those observed in the simulation based on best parameter value estimates in our model (scavenging: 4, 7, 2, and 5 weeks; mixed: $6,10,4,8$ weeks).

The sensitivity analysis revealed monotonic and statistically significant associations $(\mathrm{p}<0.001)$ between all the model parameters for the scavenging and mixed population and the herd immunity, in scenarios 1 and 2. Fecundity of hens, the survival of eggs that become chicks, and the survival of female growers becoming hens have the largest impact on the reduction of herd immunity, while better survival of male growers and cocks within the population would help to attenuate the fast decrease of herd immunity observed in both population of village chickens in scenarios 1 and 2 (Figure 3; Supplement 2).

\section{Discussion}

In this study, we modelled a scavenging and a mixed population of Indonesian village chicken populations using an aggregated extension of the classic Leslie Matrix model parameterized with available productive data. The application of this model sought to recreate population dynamics to inform the simulation of vaccine interventions and the achievable level of herd immunity. The model produced meaningful projections that allowed the simulation of vaccine interventions which highlighted the challenges of vaccinating village chickens.

27 The aggregated model approach allowed close representation of the biological processes underpinning the population turnover, despite the assumption of population dynamics of birth and removal of birds. Aggregated models have demonstrated efficiency in simulating 

some bias to transition probabilities between age-stages.

3 We compared our projections with demographic data from a survey of village chicken 4 populations in Java (ILRI, 2011) for validation purposes. The fitting of the relative age-stage 5 abundance projected for the mixed, but not the scavenging population, demonstrates that 6 Indonesia's village chicken population is not driven by a single population dynamic. When 7 duration of young and adult stages in the validation set were adjusted to match the duration of growers in the scavenging population would be only $2 / 3$ of those projected in the mixed population, which reflects the low survival of scavenging chicks. According to the same validation data, $40 \%$ of the village chicken population is replaced in 60 days; again, our simulation projected a similar replacement of $44 \%$ for the mixed population, but a more intense $55 \%$ for the scavenging population after 60 days. These results confirm that the data in ILRI (2011) and FAO (2009b) correspond to averaged traits of the Indonesian village chicken populations, and thus should not be assumed equivalent to those of traditional free-range scavenging village chickens.

Interestingly, the values of $\lambda$ scavenging and $\lambda$ mixed were close to 1 suggesting that the scavenging and mixed populations are closed, with dynamics driven by natural processes. While this is likely to be true for the scavenging, it is probably a misleading conclusion for the mixed population because purchasing of poultry is a common practice amongst the improved systems of raising village chickens in Indonesia ( ). Purchasing of birds, which contributes to the process of immigration on top of the chicks born in-farm, cannot be captured using this model approach. This limitation could be overcome in future works using an age-structured model with the inclusion of immigration and emigration at different life stages, allowing more realistic assessment of health interventions.

We assumed that new individuals coming into the population were influenza-susceptible, which is reasonable given that vaccinated-hens' chicks survive only a few days longer than the chicks 
and that maternal antibodies cannot prevent death due to HPAI H5N1 infection (De Vriese et al., 2010). In this context, we simulated vaccine interventions to estimate the herd immunity after vaccination. A field observation in Java suggested that $51.7 \%$ of the household flocks in a neighborhood must be immune to interrupt the transmission of HPAI H5N1 (ILRI, 2011). We explored this immunity threshold and an alternative observed in a confined populations (67\%), calling them lower and higher critical threshold. Our simulations showed that the herd immunity of the scavenging and mixed village chicken population quickly falls below that expected from vaccine coverage. The best scenarios simulated (Figure 2), showed that protective herd immunity would last about two months for the scavenging, and between two and two-and-a-half months for the mixed population.

These observations for village chickens in the Indonesian context are similar to those reported by Lesnoff et al (2009) for a generalized African one, viz. 16 weeks following mass vaccination, only about $30 \%$ of either the Indonesian or African village chicken populations would remain immune. Similarly, about $27 \%$ of these populations would remain immune 16 weeks after birds $>14$ day-old were vaccinated. Notably however, the rate of reduction of herd immunity in the Indonesian scavenging population is faster compared with mixed flocks due to the high rate of population replacement. These results show that vaccination coverage does not guarantee control of HPAI H5N1 and that the population turnover of village chickens would undermine the effectiveness of interventions based on current inactivated oil-emulsified whole virus vaccines. These results suggest that to achieve sustained impact, vaccination based on the current technology would need to be conducted at least every second month, an unfeasible goal given the limited coverage reported for the Indonesian sector 4 (Swayne et al., 2011).

Survival probabilities of females, males, and each age-stage could impact differently on the effectiveness of vaccine interventions. In this regard, the sensitivity analysis revealed the impact of high survivorship of chicks (chicks P) on the vaccine scenarios simulated: in the mixed population, if all birds are vaccinated, more chicks would remain contributing to sustain the herd immunity; however, if only those $>14$ day-old are vaccinated, the high survival of chicks increases both susceptible and immune, undermining the herd immunity. While the magnitude of association of chick survival with the herd immunity is the same in both vaccine interventions they do however have opposite effect (Figure 3). This suggests that vaccinating the whole mixed 
population (scenario 1) would be the most appropriate intervention; however, this conclusion

2 cannot be extrapolated to the scavenging population since the survivorship effect is not observed.

3 This difference highlights the importance of accurately identifying the relevant subgroups of the

4 village chicken population to be targeted for vaccination. In the same way, since females have

5 higher survival probabilities and become the dominant gender in both village chicken population

6 types modelled (> 50\% of the population), gender specific immunization may be one strategy to

7 consider both to maintain high herd immunity within given population and to prevent the spread

8 of HPAI H5N1 beyond it.

9 In conclusion, given that vaccination efforts aim to protect poultry and humans with a major 10 objective of preventing the emergence of a variant strain of HPAI H5N1 with pandemic 11 potential, intervention planning should account for the turnover effect of the Indonesia's village

12 chicken population in enzootic areas. We found that Indonesia's village chicken population has 13 been characterized by aggregate values of multiple systems, resulting in estimated population 14 dynamics that are not representative of traditional scavenging populations of village chickens. 15 When vaccination is planned, it would be advisable to estimate the abundance of the scavenging 16 and improved rearing systems in the area since different population dynamics have different 17 effects on vaccine effectiveness; however, our simulations confirmed that vaccination based on current technology in any of these populations will still not suffice to control HPAI H5N1. Direct contact with birds remains the main route of zoonotic infection (Van Kerkhove, 2013) and vaccinating with inadequate coverage could produce a false sense of security amongst people in contact with birds. The dramatic upsurge of human cases of HPAI H5N1 in Egypt in November 2014 highlights that epidemics at the animal-human interface are possible without major changes

23 in the virus or infection patterns, when insufficient biosecurity measures are implemented to 24 protect humans in close contact with poultry (World Health Organization, 2015b). In Indonesia, where most people continue to purchase live or plucked scavenging-backyard birds in markets or 26 from street vendors despite large poultry outbreaks (FAO, 2009a) the potential for such 27 crossover event remains. These cultural nuances make evident that this disease is best 28 approached using a One Health perspective.

\section{References}


1 Aini, I., 1990: Indigenous chicken production in South-east Asia. World Poultry Sci. J. 46, 51-

257.

3 Alders, R. G. and R. A. E. Pym, 2009: Village poultry: still important to millions, eight thousand 4 years after domestication. World Poultry Sci. J. 65, 181-190.

5 Bouma, A., A. T. Muljono, A. Jatikusumah, A. Nell, S. Mudjiartiningsih, I. Dharmayanti, E. S.

6 Siregar, I. Claassen, G. Koch and J. Stegeman, 2008: Field trial for assessment of avian

7 influenza vaccination effectiveness in Indonesia. Rev. Sci. Tech. 27, 633-642.

8 Caswell, H., 2001: Matrix population models: construction, analysis, and interpretation. Sinauer 9 Associates, Sunderland, Massachusetts.

10 Crouse, D. T., L. B. Crowder and H. Caswell, 1987: A stage-based population model for 11 loggerhead sea turtles and implications for conservation. Ecology 68, 1412-1423.

12 Cumming, R.B., 1992: Village chicken production: problems and potential. In: Proceedings of an 13 international workshop on Newcastle disease in village chickens: control with thermostable oral 14 vaccines. Kuala Lumpur, Malaysia, 6-10 October 1991, p. 21-24.

De Vriese, J., M. Steensels, V. Palya, Y. Gardin, K. M. Dorsey, B. Lambrecht, S. Van Borm and T. Van Den Berg, 2010: Passive protection afforded by maternally-derived antibodies in 17 chickens and the antibodies' interference with the protection elicited by avian influenza18 inactivated vaccines in progeny. Avian Dis. 54, 246-252.

Diwyanto, K. and S. Iskandar, 1999: Kampung chickens: A key part of Indonesia's livestock of sector. Central Research Institute for Animal Sciences and Research Institute for Animal

21 Production. Bogor, Indonesia.

22 EMPRES-i FAO, 2015: H5N1 HPAI disease events in Indonesia. Food and Agriculture 23 Organization of the United Nations. Available at: http://empres-i.fao.org/eipws3g/\# (accessed 24 on 03 Jun 2015). 
EMPRES/FAO-GLEWS, 2012: H5N1 HPAI global overview April-June 2012. Food and

2 Agriculture Organization of the United Nations. Available at:

3 http://www.fao.org/docrep/016/ap387e/ap387e.pdf (accessed on 31 Mar 2014).

4 EMPRES/FAO, 2012: Focus on. Update on the continuous spread and expansion of H5N1

5 highly pathogenic avian influenza. Food and Agriculture Organization of the United Nations.

6 Available at: http://www.fao.org/docrep/019/i3610e/i3610e.pdf (accessed on 6 Jan 2015).

7 FAO, 2008a: Biosecurity for highly pathogenic avian influenza. Issues and options. FAO Animal

8 Production and Health Paper. FAO, Rome, Italy.

9 FAO, 2008b: Local chicken genetic resources and production systems in Indonesia. Prepared by 10 Muladno Muladno. GCP/RAS/228/GER Working paper No. 6. Rome, Italy.

11 FAO, 2009a: Consumer preferences for poultry products in Indonesia. Prepared by Muladno 12 Muladno and O. Thieme. GCP/RAS/228/GER Working paper No. 12. Rome, Italy.

13 FAO, 2009b: Production systems and poultry genetic resources utilized by small producers in 14 areas of West Java and Central Java, Indonesia. Prepared by Muladno Muladno and O. Thieme. 15 GCP/RAS/228/GER Working paper No. 11. Rome, Italy.

FAO/OIE/WHO, 2010a: Executive summary. The 2008 FAO-OIE-WHO joint technical consultation on avian influenza at the human animal interface. Influenza Other Respir. Viruses 4 Suppl 1, ii-ii.

FAO/OIE/WHO, 2010b: FAO/OIE/WHO joint scientific consultation and other emerging zoonotic diseases at the human-animal interface. Meeting summary and key findings, Verona,

Farnsworth, M. L., S. Fitchett, M. M. Hidayat, C. Lockhart, C. Hamilton-West, E. Brum, S.

Angus, B. Poermadjaja and J. Pinto, 2011: Metapopulation dynamics and determinants of $25 \quad 206-217$. 
1 Fine, P., K. Eames and D. L. Heymann, 2011: 'Herd immunity': a rough guide. Clin. Infect. Dis. $2 \quad 52,911-916$.

3 Gunaratne, S., A. Chandrasiri, W. M. Hemalatha and J. Roberts, 1993: Feed resource base for

$4 \quad$ scavenging village chickens in Sri Lanka. Trop Anim Health Prod. 25, 249-257.

5 Handaka, 2009: Towards sustainable agricultural mechanization in Indonesia. Tech Monitor.

6 Available at: http://www.techmonitor.net/tm/images/d/d4/09jan_feb_sf4.pdf (accessed on 15

7 Jan 2016).

8 ILRI, 2011: Operational research in Indonesia for more effective control of highly pathogenic 9 avian influenza. ILRI project report. ILRI, Nairobi, Kenya.

10 Kingston, D., 1980: The productivity of scavenging chicken in some villages of West Java, 11 Indonesia. In: Proceedings of the South Pacific Poultry Science Convention. Auckalnd, New 12 Zealand, 13-16 October 1980, p. 228-237.

Kingston, D., B. Gunawan and D. Creswell, 1982: Indigenous Chickens in Indonesia: Population 14 and production characteristics in five villages of West Java. Report No. 2. Research Institute for 15 Animal Production, Bogor, Indonesia.

Lefkovitch, L., 1965: The study of population growth in organisms grouped by stages. 17 Biometrics 21, 1-18.

18 Leslie, P., 1948: Some further notes on the use of matrices in population mathematics. 19 Biometrika 35, 213-245.

20 Leslie, P. H., 1945: On the use of matrices in certain population mathematics. Biometrika 33, $21 \quad 183-212$.

22 Lesnoff, M., M. Peyre, P. C. Duarte, J. F. Renard and J. C. Mariner, 2009: A simple model for 23 simulating immunity rate dynamics in a tropical free-range poultry population after avian 24 influenza vaccination. Epidemiol. Infect. 137, 1405-1413. 
Maas, R., S. Rosema, D. Van Zoelen and S. Venema, 2011: Maternal immunity against avian

2 influenza H5N1 in chickens: limited protection and interference with vaccine efficacy. Avian

3 Pathol. 40, 87-92.

4 Marino, S., I. B. Hogue, C. J. Ray and D. E. Kirschner, 2008: A methodology for performing 5 global uncertainty and sensitivity analysis in systems biology. J. Theor. Biol. 254, 178-196.

6 McKay, M. D., R. J. Beckman and W. J. Conover, 1979: Comparison of three methods for 7 selecting values of input variables in the analysis of output from a computer code. 8 Technometrics 21, 239-245.

9 Parker, T. H. and K. Winker, 2005: No evidence for adaptative differential sex allocation in Red Junglefowl (Gallus gallus). The Auk 122, 1161-1168.

R Development Core Team, 2014: R: A language and environment for statistical computing. R 12 Foundation for Statistical Computing, Vienna, Austria.

13 Sims, L., J. Domenech, C. Benigno, S. Kahn, A. Kamata, J. Lubroth, V. Martin and P. Roeder, 14 2005: Origin and evolution of highly pathogenic H5N1 avian influenza in Asia. Vet. Rec. 157, 159-164.

Siregar, E. S., J. W. Darminto and A. Bouma: The vaccination programme in Indonesia. Dev. 17 Biol. (Basel) 130, 151-158.

Skalski, J. R., K. E. Ryding and J. Millspaugh, 2010: Wildlife demography: analysis of sex, age, and count data. Academic Press, Burlington, MA.

20 Swayne, D., G. Pavade, K. Hamilton, B. Vallat and K. Miyagishima, 2011: Assessment of national strategies for control of high-pathogenicity avian influenza and low-pathogenicity 22 notifiable avian influenza in poultry, with emphasis on vaccines and vaccination. Rev. Sci. 23 Tech. 30, 839-870.

24 Tiensin, T., M. Nielen, H. Vernooij, T. Songserm, W. Kalpravidh, S. Chotiprasatintara, A. 25 Chaisingh, S. Wongkasemjit, K. Chanachai and W. Thanapongtham, 2007: Transmission of the 
highly pathogenic avian influenza virus H5N1 within flocks during the 2004 epidemic in

2 Thailand. J. Infect. Dis. 196, 1679-1684.

3 Unger, F., W. Priyono, E. Siregar, M. Azhar, B. Bett, M. McLaws, C. Jost and J. Mariner, 2012:

4 Population dynamics in kampong chicken and consequences for HPAI vaccination: results of a

5 field trial in Java. In: Proceedings of the 13th conference of the International Society for

6 Veterinary Epidemiology and Economics. Maastricht, Netherlands, 20-24 August 2012, p. 288

7 Van Kerkhove, M. D., 2013: Brief literature review for the WHO global influenza research

8 agenda-highly pathogenic avian influenza H5N1 risk in humans. Influenza Other Respir.

9 Viruses 7, 26-33.

Ward, M., D. Maftei, C. Apostu and A. Suru, 2009: Estimation of the basic reproductive number (R0) for epidemic, highly pathogenic avian influenza subtype H5N1 spread. Epidemiol. Infect. $137,219-226$.

World Health Organization, 2013: Update on human cases of influenza at the human-animal interface, 2012. Wkly.Epidemiol.Rec. 88, 137-144.

World Health Organization, 2015a: Cumulative number of confirmed human cases of avian influenza $\mathrm{A}(\mathrm{H} 5 \mathrm{~N} 1)$ reported to $\mathrm{WHO}$. Available at: http://www.who.int/influenza/human_animal_interface/EN_GIP_20150106CumulativeNumber H5N1cases.pdf (accessed on 13 Jan 2015).

World Health Organization, 2015b: Egypt: upsurge in H5N1 human and poultry cases but not change in transmission pattern. Available at: http://www.emro.who.int/egy/egyptnews/upsürge-h5n1-human-poultry-cases-may-2015.html (accessed on 30 May 2015).

Zinsstag, J., E. Schelling, D. Waltner-Toews, M. Whittaker and M. Tanner, 2015: One Health: the theory and practice of integrated health approaches. CABI, Boston, MA.

This article is protected by copyright. All rights reserved 
Table 1. Demographic parameters for the Indonesia's Scavenging and Mixed village chicken population, and those of village chickens in the African context.

\begin{tabular}{lccc}
\hline Parameter & Scavenging & Mixed & African free-range \\
\hline Eggs/Hen/Year & 70.4 & 45 & 35 \\
Duration of egg stage (weeks) & 3 & 3 & 5 \\
Duration of chicks stage (weeks) & 4 & 4 & 10 \\
Duration female grower stage (weeks) & 20 & 20 & 14 \\
Duration male grower stage (weeks) & 20 & 20 & 10 \\
Maximum survival hens (years) & 2 & 1 & 4 \\
Maximum survival cocks (years) & 1.5 & 1 & 87.3 \\
Survival Eggs* (weekly \%) & 88.6 & 93.0 & 88.0 \\
Survival chicks (weekly \%) & 69.9 & 93.5 & 95.0 \\
Survival female growers (weekly\%) & 94.0 & 94.0 & 86.1 \\
Survival male growers (weekly\%) & 92.0 & 92.0 & 98.6 \\
Survival hens (weekly \%) & 97.6 & 93.0 & 98.3 \\
Survival Cocks (weekly\%) & 95.7 & 91.5 & \\
\hline After & & & 2 \\
\hline
\end{tabular}

*After eggs used, broken, and hatchability. Calculated from Lesnoff et al (2009)

This article is protected by copyright. All rights reserved 
Table 2. Model's steady-state relative age-stage abundance for the Scavenging and Mixed Indonesia's village chicken population compared to field data reported by ILRI (2011).

\begin{tabular}{lccc}
\hline Age-stage & Scavenging & Mixed & ILRI* \\
\hline Chicks (f \& m) & $38 \%$ & $25 \%$ & $25 \%$ \\
Female growers & $21 \%$ & $32 \%$ & $57 \% * *$ \\
Male growers & $18 \%$ & $28 \%$ & \\
Hens & $16 \%$ & $10 \%$ & $12 \%$ \\
Cocks & $7 \%$ & $6 \%$ & $6 \%$ \\
Total & $100 \%$ & $100 \%$ & $100 \%$ \\
\hline
\end{tabular}

*Abundance of growers and adults recalculated from ILRI to fit duration of these age-stages as defined in the model. ** Female and male growers together.
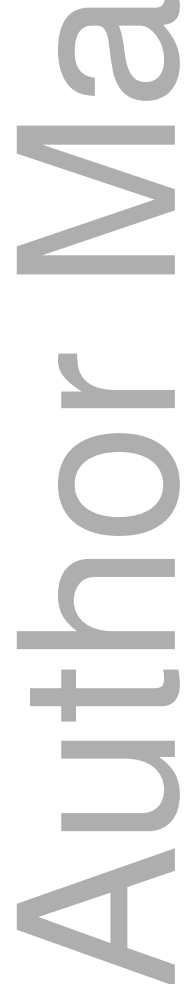


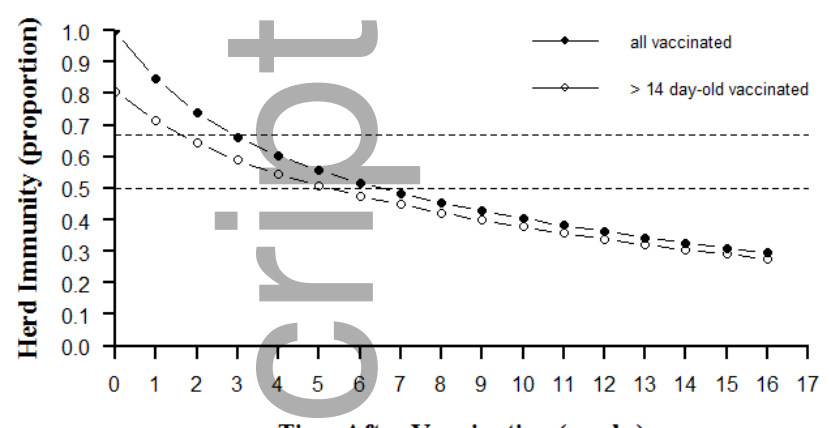

Time After Vaccination (weeks)

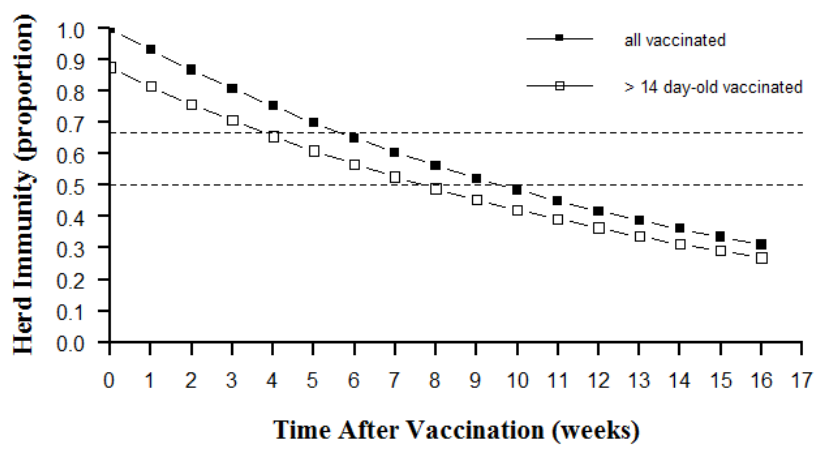

Figure 1. Herd immunity after a perfect vaccination of a population of scavenging (left) or semicommercial village chickens (right). Dashed lines represent the higher and lower critical herd immunity thresholds that would prevent $\mathrm{H} 5 \mathrm{~N} 1$ reemergence.
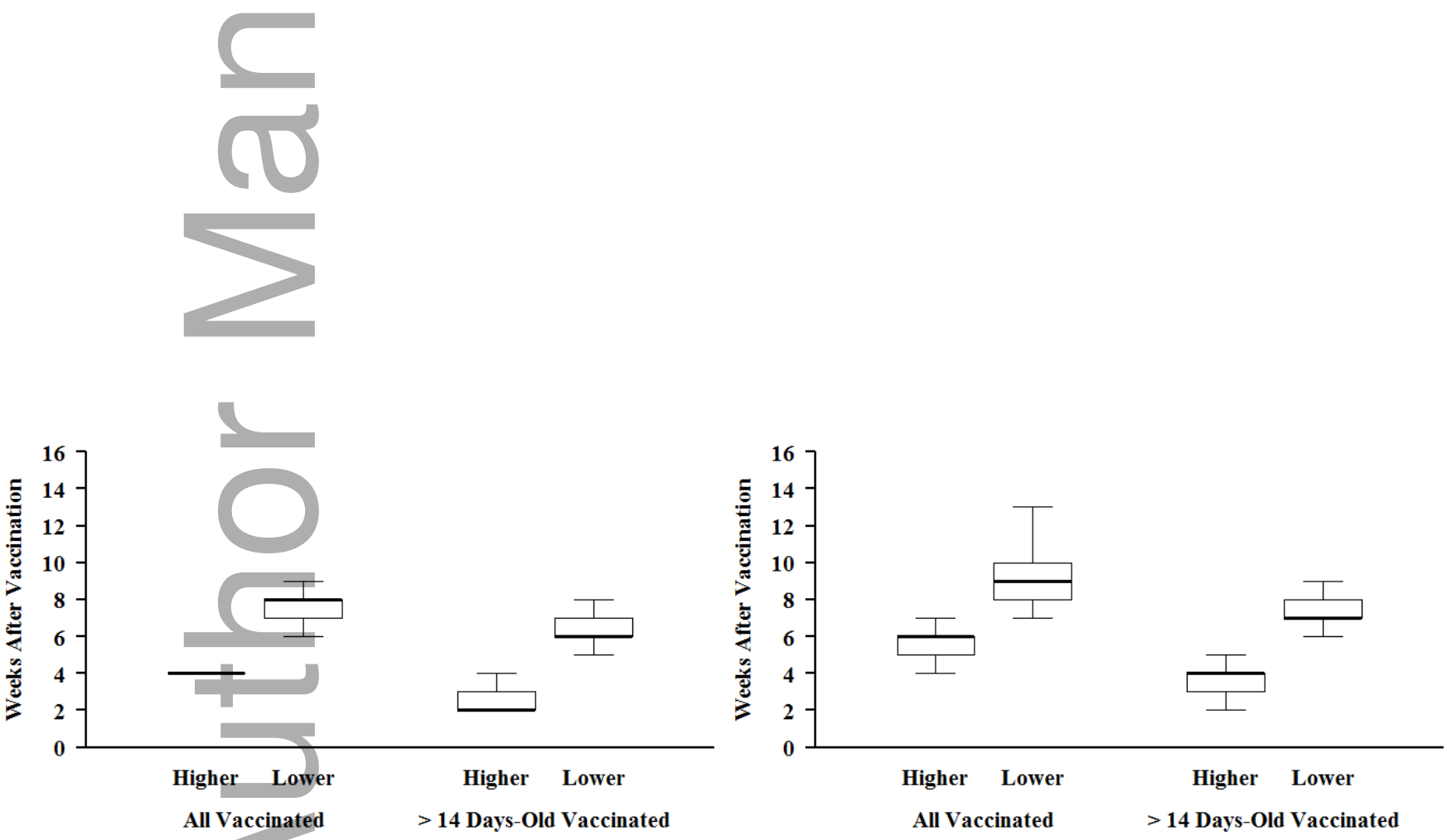

Figure 2. Weeks for the herd immunity to reach the higher $(67 \%)$ and lower (50\%) critical thresholds after a perfect vaccination of a scavenging (left) or semi-commercial (right) population of village chickens. 

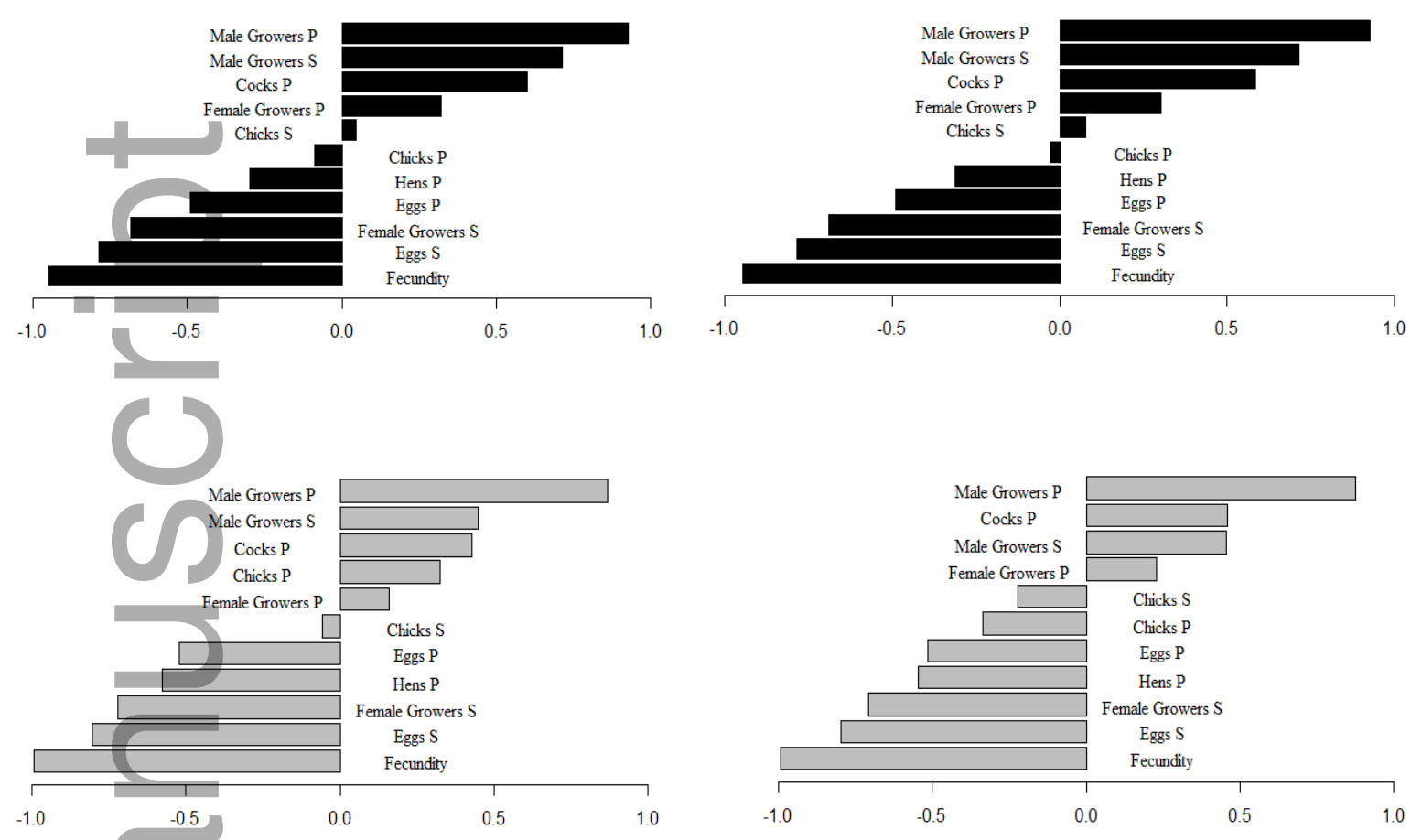

Figure 3. Partial rank correlation coefficient between parameters and herd immunity when all (left), or those over 14 day-old (right) were vaccinated in a scavenging (black) or a semicommercial (grey) population of village chickens.

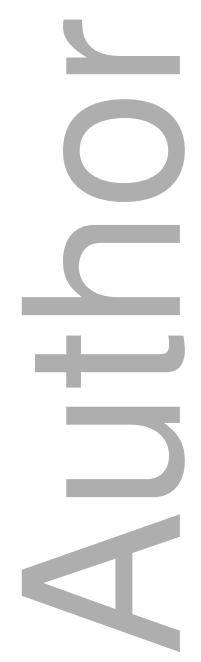




\section{University Library}

\section{- M M N E R VA A gateway to Melbourne's research publications}

Minerva Access is the Institutional Repository of The University of Melbourne

Author/s:

Villanueva-Cabezas, JP;Campbell, PT;McCaw, JM;Durr, PA;McVernon, J

Title:

Turnover of Village Chickens Undermines Vaccine Coverage to Control HPAI H5N1

Date:

2017-02-01

Citation:

Villanueva-Cabezas, J. P., Campbell, P. T., McCaw, J. M., Durr, P. A. \& McVernon, J. (2017).

Turnover of Village Chickens Undermines Vaccine Coverage to Control HPAI H5N1.

ZOONOSES AND PUBLIC HEALTH, 64 (1), pp.53-62. https://doi.org/10.1111/zph.12282.

Persistent Link:

http://hdl.handle.net/11343/291462 